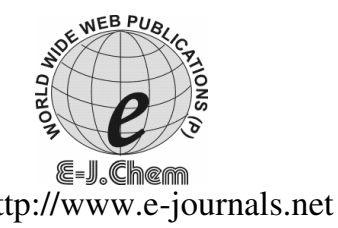

ISSN: 0973-4945; CODEN ECJHAO

E-Journal of Chemistry

http://www.e-journals.net

2010, 7(4), 1412-1420

\title{
Electrolytic Recovery of Nickel from Spent Electroless Nickel Bath Solution
}

\author{
R. IDHAYACHANDER and K. PALANIVELU* \\ Centre for Environmental Studies, \\ Anna University Chennai, Chennai-600025, India. \\ kpvelu@annauniv.edu
}

Received 11 April 2009; Accepted 5 June 2009

\begin{abstract}
Plating industry is one of the largest polluting small scale industries and nickel plating is among the important surface finishing process in this industry. The waste generated during this operation contains toxic nickel. Nickel removal and recovery is of great interest from spent bath for environmental and economic reasons. Spent electroless nickel solution from a reed relay switch manufacturing industry situated in Chennai was taken for electrolytic recovery of nickel. Electrolytic experiment was carried out with mild steel and gold coated mild steel as cathode and the different parameters such as current density, time, mixing and $\mathrm{pH}$ of the solution were varied and recovery and current efficiency was studied. It was noticed that there was an increase in current efficiency up to $5 \mathrm{~A} / \mathrm{dm}^{2}$ and after that it declines. There is no significant improvement with mixing but with modified cathode there was some improvement. Removal of nickel from the spent electroless nickel bath was $81.81 \%$ at $5 \mathrm{~A} / \mathrm{dm}^{2}$ and $\mathrm{pH} 4.23$. Under this condition, the content of nickel was reduced to $0.94 \mathrm{~g} / \mathrm{L}$ from $5.16 \mathrm{~g} / \mathrm{L}$. with $62.97 \%$ current efficiency.
\end{abstract}

Keywords: Electroless bath, Nickel, Electrolytic reduction, Nickel Recovery, Current efficiency.

\section{Introduction}

Environmental pollution is one of the most serious problems faced by mankind today. Damage to the environment has been growing steadily year by year as a result the quality of life and health of the human is affected. Electronic industry is one of the important industry which uses nickel in bath for nickel plating. The nickel present wastewater is treated by different techniques like precipitation ${ }^{1}$, adsorption ${ }^{2-4}$ and ion-exchange ${ }^{5}$.

The electroless nickel plating process, also called autocatalytic nickel deposition; it deposits a uniform coating onto catalytic surfaces, regardless of the shape of the part. Once a primary layer of metal has formed on the substrate, which layer, as well as each subsequent layer, becomes the catalyst that causes the reaction to continue. Electroless nickel plating, in contrast to nickel electroplating, does not use external electric 
current to produce a deposit. Deposition occurs in an aqueous solution containing metal ions, a reducing agent and a catalyst (part). Chemical reactions on the surface of the catalytic part being plated cause deposition of the metal or alloy. The most common reducing agent used in this process is sodium hypophosphite ${ }^{6}$. Both nickel and phosphorus are reduced simultaneously and the coating produced is phosphorus in nickel. The nickel ion becomes the coating and the hypophosphite is oxidized to the phosphate continually in the electroless nickel plating process. Thus, adding nickel sulfate and sodium hypophosphite to the plating bath is necessary to keep the plating reaction going. Phosphite, sulfate, sodium and other harmful components gradually accumulate in the bath during the process of electroless nickel plating (EN). When the concentrations of these components reach a certain level, the bath cannot work any longer and it should be discarded.

Various studies have been conducted to recover nickel by electrolytic technique because it is clean and environment friendly technology. It is reported $60 \%$ recovery in a system where solutions with $5.5 \mathrm{~g} / \mathrm{L}$ initial concentration ${ }^{7}$ was treated and $200 \mathrm{mg} / \mathrm{L}$ final concentration was achieved, $90 \%$ of nickel was recovered from the initial concentration of $2 \mathrm{~g} / \mathrm{L}$ with $74 \%$ current efficiency from the rinse water ${ }^{8}$ emerging from nickel-plating bath, $65 \%$ of nickel was recovered at the cell voltage of $3.7 \mathrm{~V}$ in just 15 minutes from industrial hydrogenated vegetable oil ${ }^{9}$ using static sheet electrode couples electrolysis, $80 \%$ nickel recovery at the end of a 24-h electrolysis operation, with 1.8 $2.0 \mathrm{mg} / \mathrm{L}$ initial concentration ${ }^{10}$. In a work by Ripperger ${ }^{11}$, a final nickel concentration of less than $0.1 \mathrm{mg} / \mathrm{L}$ was attained when solutions with 200 and $400 \mathrm{mg} / \mathrm{L}$ initial nickel concentrations were treated by electro microfiltration process. Most of the study is done using the electroplating nickel solution. Present study was carried out using spent midphosphorus electroless nickel solution with modified electrode (gold plated) to improve the efficiency and to reduce the hydrogen evolution due to its high hydrogen over potential in the recovery of metallic nickel.

\section{Experimental}

The spent electroless nickel bath of 9 metal turn over was collected from a reed switch manufacturing company located near Chennai. In this industry electroless nickel coating is done over nickel iron wire to protect it from corrosion.

\section{Equipments}

The XRF spectrum was taken at Switching Technology Gunther Ltd industry using SII, SFT9100 XRF machine. Scanning electron microscope (SEM; JEOL JSM-6360) was used for taking photographs of samples.

\section{Nickel Determination}

The nickel was determined by complexometric titration with EDTA and using murexide as indicator $^{12}$.

\section{Electrolytic recovery studies of nickel}

The experiments were conducted by batch process using single compartment undivided 3 electrode glass cell of $250 \mathrm{~mL}$ capacity. The anode and cathode were positioned vertically and parallel to each other. The material used as the anode was platinum coated titanium mesh of $4 \times 1.5 \mathrm{~cm}$ supplied by M/s. Umicore Galvanotechnik GmbH, Germany. Mild Steel of $4 \times 1 \mathrm{~cm}$ supplied by M/s L.G. Balakrishnan and Bros Ltd, Gudalur, India and 0.9 
micrometer gold plated mild steel of $4 \times 1 \mathrm{~cm}$ were used as the working cathode material. Saturated calomel electrode was used as reference electrode. A stabilized DC power supply supplied by M/s Herrmann, Germany was used as the source of power for the experiments. The current efficiency of the electrolytic nickel recovery process was calculated using the formula shown below.

$$
\begin{gathered}
\eta_{c}=\left(W_{a} / W_{t}\right) x 100 \\
\mathrm{~W}_{\mathrm{a}}=\text { Actual metal deposited }(\mathrm{g}) \\
\mathrm{W}_{\mathrm{t}}=\text { Metal expected to be deposited }(\mathrm{g}) \\
\eta_{\mathrm{c}}=\text { Current efficiency (percentage) }
\end{gathered}
$$

The nickel recovery efficiency was calculated by the given formula

$$
\eta_{r}=\left(\frac{C_{0}-C_{f}}{C_{0}}\right) x 100
$$

$\mathrm{C}_{0}=$ Initial Concentration of nickel in the sample $(\mathrm{g} / \mathrm{L})$

$\mathrm{C}_{\mathrm{f}}=$ Final concentration of nickel in the sample after electrolysis $(\mathrm{g} / \mathrm{L})$

$\eta_{\mathrm{r}}=$ Recovery efficiency (percentage)

\section{Results and Discussion}

\section{Characteristics of spent bath}

The characteristics of the spent electroless nickel after 9 metal turnovers were studied and it was observed (Table 1) that the effluent was acidic with high nickel content. The high nickel content and presence of large amount of other ions like sulphate and chloride, makes it highly conductive. The high conductivity prevents the necessity for addition of further electrolyte. From the Table 1, it could be observed that the spent solution contains chloride which was not present in the fresh bath; this indicates that there was some carry over of chloride from the $20 \% \mathrm{HCl}$ acid activation pre treatment operation.

Table 1. Characteristics of spent electroless nickel bath

\begin{tabular}{clcl}
\hline S.No & Characteristics & Unit & Sample \\
\hline 1 & pH & & 4.23 \\
2 & Nickel & g/L & 5.16 \\
3 & Sodium hypophosphite & $\mathrm{g} / \mathrm{L}$ & 13.75 \\
4 & Sulphate & $\mathrm{g} / \mathrm{L}$ & 18.00 \\
5 & Chloride & $\mathrm{g} / \mathrm{L}$ & 1.90 \\
6 & Total solids & $\mathrm{g} / \mathrm{L}$ & 155.06 \\
7 & Total suspended solids & $\mathrm{g} / \mathrm{L}$ & 8.99 \\
8 & Total dissolved solids & $\mathrm{g} / \mathrm{L}$ & 146.07 \\
9 & Conductivity & $\mathrm{mS} / \mathrm{cm}$ & 59.25 \\
\hline
\end{tabular}

\section{Characteristics of modified electrode}

The plain mild steel cathode material used for electrolytic experiment was examined under scanning electron microscope (Figure 1) and it was observed that the surface was not uniform and it also shows some pit marks. Flash coating of gold was deposited on the mild steel using the acidic gold strike bath. The coated thickness of the gold was measured using the XRF machine and found to be 0.09 micrometer. 


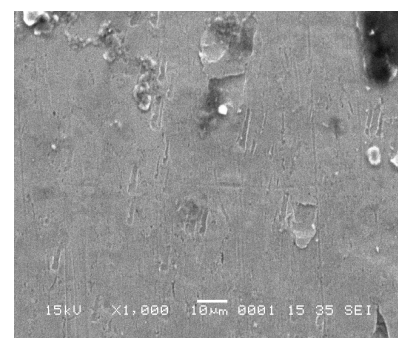

Figure 1. SEM image of mild steel

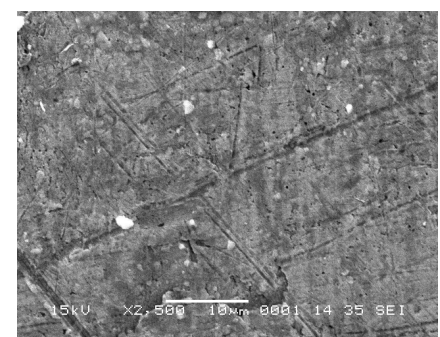

Figure 2. SEM image of gold coated mild steel

From the image (Figure 2) taken by scanning electron microscope it was observed that the deposited gold coating is porous. Since gold has high hydrogen over potential, it was deposited over mild steel to reduce the hydrogen evolution to increase the current efficiency during electrochemical treatment and considered for the study.

\section{Electrolytic recovery studies}

Electrochemical reduction technique was used to recover the nickel from the spent electroless nickel solution. The anode used for the experiment was platinum coated titanium. This inert anode serve for the following functions: they are required to complete the electric circuit and introduce current into the bath, i.e., they serve to remove the electrons introduced at the cathode. The cathodes used are mild steel and gold coated mild steel. The nickel deposited on the cathode do not deposit as continues sheets from one part of the cathode to the others, metal ions, carrying with them their accompanying ligands (water molecules or complexing agents), attach themselves at certain preferred sites, losing in the process some of the water or other ligands, forming bonds with the cathode surface while their charges are partially neutralized. These anions diffuse over the surface to various irregularities in the surface such as kinks, edges, or steps, where they are now incorporated into the metal lattice.

As these growth sites travel across the face of the crystal, monoatomic growth layer are produced, they grow until they encounter adsorbed impurities, where they agglomerate to form growth stacks consisting of several layers. This lateral growth proceeds until several neighboring lattice meet to form a boundary at the constant line, the individual structures thus formed are called grains. Further growth proceeds outward and the thickness of the deposit are thus built up. The steps involved from metal ion in solution to metal atom in the lattice are given below ${ }^{4}$.

1. Arrival of metal ions at the double layer.

2. Release of some ions, one by one, to form an anion.

3. Deposition at a flat area of the cathode.

4. Lateral movement to a final place in the metal lattice.

The main electrochemical reactions took place during nickel recovery process are

\section{Cathodic reaction}

Anodic reaction

$$
\begin{aligned}
& \mathrm{Ni}^{2+}+2 \mathrm{e}-\rightarrow \mathrm{Ni}^{0} \\
& \mathrm{E}=-0.27+0.0591 \log \mathrm{C}_{\mathrm{Ni}}^{2+}
\end{aligned}
$$

$$
\begin{aligned}
& \mathrm{H}_{2} \mathrm{O} \rightarrow 2 \mathrm{H}^{+}+1 / 2 \mathrm{O}_{2}+2 \mathrm{e}- \\
& \mathrm{E}=1.229-0.0591 \mathrm{pH}
\end{aligned}
$$

Overall reaction

$$
\mathrm{Ni}^{2+}+\mathrm{H}_{2} \mathrm{O} \rightarrow \mathrm{Ni}+2 \mathrm{H}^{+}+1 / 2 \mathrm{O}_{2}
$$


From the equation above it could be observed that the standard reduction potential of nickel is $-0.27 \mathrm{~V}$ and for the practical reduction of nickel metal, we need more voltage which is depend upon the concentration of the nickel ions in the solution and the standard oxidation potential of oxygen is $+1.229 \mathrm{~V}$ and this voltage is depend on the $\mathrm{pH}$ of the solution. The potential Vs. current density curve for hydrogen has an important role in determining the electrolysis conditions of metals, such as nickel, which are below hydrogen in the EMF series

The prerequisite in the electrolysis of these metals, which are below hydrogen in the EMF series, is to carry out the operation at high current densities (though limited by high energy consumption) and at the lowest possible temperature. The critical parameter for attaining high current efficiencies in nickel electrolysis is the $\mathrm{pH}$ of the electrolyte.

\section{Effect of current density on metal recovery}

Current efficiency and metal recovery efficiency was studied by varying the current density and keeping the contact time constant at $3 \mathrm{~h}$ with unmodified electrode. As the current density is increased, the rate at which the ions are removed from the cathode vicinity increases. This is replaced by the diffusion of ions from the bulk. This cannot go on indefinitely and a stage will be reached at which the diffusion rate is high and at this condition efficiency will be high. When the current density is increased further, some other ion, usually $\mathrm{H}^{+}$is discharged together with the metal ions and the current will be wasted. This result in a rise in the cathode potential, since a fraction of the current is spent to produce hydrogen, the current efficiency for metal deposition reduced.

Apart from the hydrogen gas evolution other reducible ions may also cause low cathode efficiency, in this electrolytic experiment the presence of nitrate in the solution takes some current for the reduction of nitrate ion to lower valency species, such as nitrite, nitrogen or ammonia, which lowers the current efficiency. The highest current up to which the current efficiency for metal deposition continuous to be maximum is called limiting current density. From the Table 2, it can be noticed that $5 \mathrm{~A} / \mathrm{dm}^{2}$ current density has maximum current efficiency and after that it declines. It is also noticed that there is steady increase of recovery efficiency up to $6 \mathrm{~A} / \mathrm{dm}^{2}$ and after that it decreases.

\section{Effect of modified cathode on metal recovery}

Hydrogen over potential was one of the important parameter used to determine the current efficiency and this hydrogen overvoltage depends on the nature of the cathode surface. As such it is not possible to deposit zinc over cast iron due to its less hydrogen overvoltage, but it is possible by flash (flash means to make a very thin initial deposit) the cast iron with tin deposit, on which hydrogen overvoltage is high and which therefore can accept zinc deposit. The same principle was followed and in order to achieve high hydrogen over potential at cathode surface the electrode was modified with thin layer of gold coating.

Table 2. Effect of current density on metal recovery efficiency with unmodified electrode

\begin{tabular}{ccccc}
\hline S.No & $\begin{array}{c}\text { Current density, } \\
\mathrm{A} / \mathrm{dm}^{2}\end{array}$ & $\begin{array}{c}\text { Current applied, } \\
\text { Amps }\end{array}$ & $\begin{array}{c}\text { Current } \\
\text { efficiency, \% }\end{array}$ & $\begin{array}{c}\text { Recovery } \\
\text { efficiency, \% }\end{array}$ \\
\hline 1 & 3.0 & 0.27 & 78.71 & 13.62 \\
2 & 4.0 & 0.36 & 72.46 & 18.18 \\
3 & 4.5 & 0.40 & 76.50 & 20.44 \\
4 & 5.0 & 0.45 & 80.18 & 24.99 \\
5 & 5.5 & 0.50 & 78.50 & 22.74 \\
6 & 6.0 & 0.54 & 75.87 & 27.22 \\
7 & 7.0 & 0.63 & 55.78 & 22.71 \\
8 & 8.0 & 0.72 & 39.82 & 20.41 \\
\hline
\end{tabular}


Experiment was carried out with and without gold plated mild steel as cathode for the duration of $3 \mathrm{~h}$ at the current density of $5 \mathrm{~A} / \mathrm{dm}^{2}$. It is noticed from the Table 3 that there was small increase in the current and recovery efficiency for gold coated electrode than mild steel.

Table 3. Effect of cathode material on current and recovery efficiency

\begin{tabular}{clcc}
\hline S.No & Cathode material & $\begin{array}{c}\text { Current } \\
\text { efficiency, } \%\end{array}$ & $\begin{array}{c}\text { Recovery } \\
\text { efficiency, \% }\end{array}$ \\
\hline 1 & Mild steel & 78.10 & 13.62 \\
2 & Gold plated Mild steel & 81.36 & 15.60 \\
\hline
\end{tabular}

Effect of mixing on metal recovery

When we pass the current through the solution, $\mathrm{Ni}^{2+}$ ions in the solution near the cathode get discharged on the cathode as nickel atom. This results in a decrease in the $\mathrm{Ni}^{2+}$ ions concentration in the immediate vicinity of the cathode, this fall in nickel ion concentration was made up by transporting the ions from the bulk of the electrolyte. This can be accomplished in three ways: by convection, migration and diffusion. Convection depends on temperature difference in the different zones of the solution, since there was no significant temperature difference; the contribution of convection to the supply of ions was practically nil. Migration of ions depends on the number and nature of ions present, since the spent solution was highly acidic most of the current was carried by them and only small quantity was left to be carried by nickel ions, so the available of nickel ions at cathode due to migration was small.

Diffusion is the movement of a chemical species, either ionic or uncharged, through the solution as a result of a concentration gradient. It is a result of random motion of the ions or molecules, this motion tends to produce more uniform distribution of the various species throughout the solution. Thus the depletion of a species next to the cathode results in a movement of that species from the bulk of the solution toward the cathode.

This region next to the electrode, where the concentration of chemical species differs from its concentration in the bulk solution, is called the diffusion layer. The boundary between the diffusion layer and the bulk of solution is not a sharp line; it has been arbitrarily as the region where the concentration of any species differs from its concentration in the bulk of solution by 1 percent or more. In this region, as has stated, convection is negligible.

The rate of diffusion, expressed in gram-ions or moles per square centimeter per second is proportional to the concentration gradient at the electrode. The proportionality constant $\mathrm{D}$ is called diffusion constant, expressed in square centimeter per second. The rate may be expressed as

$$
\mathrm{R}=\mathrm{D}\left(\mathrm{C}_{\mathrm{o}}-\mathrm{C}_{\mathrm{E}}\right) / \mathrm{dN}
$$

where $\mathrm{C}_{\mathrm{o}}$ is the bulk concentration, $\mathrm{C}_{\mathrm{E}}$ is the concentration at the electrode surface, and $\mathrm{dN}$ is the effective thickness of the diffusion layer, sometimes called as Nernst thickness. As dN decreases, diffusion rate increases. Agitation decreases $\mathrm{dN}$, thus increasing the diffusion rate. In the absence of agitation, $\mathrm{dN}$ is about $0.2 \mathrm{~mm}$ and as agitation is increased, this value can drops up to $0.015 \mathrm{~mm}$. From this it was very clear that the replenishment of nickel ions removed at the cathode was almost entirely depend on diffusion and it is also observed that without mixing, diffusion was unable to keep pace with ions removed by discharged at cathode. So the experiment was conducted with the mixing of electrolyte using magnetic stirrer to decrease the diffusion layer and compared with the experimental results of electrolyte without mixing.

From the results presented in the Table 4, it can be seen that there was only small increase in the current efficiency, due to mixing of electrolyte. Since the volume of electrolyte was very small $(200 \mathrm{~mL})$ the effect of mixing was not very significant. However, for large volume as with actual industrial effluent mixing is recommended to avoid concentration polarisation. 
Table 4. Effect of Mixing on Current and recovery efficiency with unmodified electrode

\begin{tabular}{ccccc}
\hline S.No & Mixing & $\begin{array}{c}\text { Current applied, } \\
\text { Amps }\end{array}$ & $\begin{array}{c}\text { Current } \\
\text { efficiency, \% }\end{array}$ & $\begin{array}{c}\text { Recovery } \\
\text { efficiency, \% }\end{array}$ \\
\hline 1 & Without mixing & 0.27 & 78.7 & 13.42 \\
2 & With mixing & 0.27 & 79.3 & 13.62 \\
\hline
\end{tabular}

Effect of $p H$ on metal recovery

$\mathrm{pH}$ is one of the important parameter in metal deposition. It influences the hydrogen discharge potential, it controls the composition of the complex containing the depositing metal, the adsorption of addition agents, and the cathode and anode efficiencies. It also known to affect stress and hardness in the deposit this effect was probably an indirect result of the inclusion in the deposit.

$\mathrm{pH}$ both influences and influenced by the efficiency of metal dissolution and deposition at both electrodes. $\mathrm{pH}$ of the bath was varied using $1 \mathrm{~N} \mathrm{NaOH}$ solution and the experiment was carried out for $3 \mathrm{~h}$ keeping the other parameter constant. The results presented in the Table 5 shows as the $\mathrm{pH}$ increases the current and the recovery efficiency decreases. It was also observed at $7 \mathrm{pH}$ the nickel starts to precipitate as nickel hydroxide and as a result the current efficiency decreases drastically.

Table 5. Effect of $\mathrm{pH}$ on current and recovery efficiency

\begin{tabular}{cccc}
\hline S.No & $\mathrm{pH}$ & Current efficiency, $\%$ & Recovery efficiency, $\%$ \\
\hline 1 & 4.23 & 80.18 & 24.99 \\
2 & 5.00 & 78.11 & 22.71 \\
3 & 6.00 & 75.01 & 20.44 \\
4 & 7.00 & 67.50 & 15.89 \\
\hline
\end{tabular}

Effect of contact time on metal recovery

For the constant current density of $5 \mathrm{~A} / \mathrm{dm}^{2}$ the experiment was carried out for different contact time. The results presented in the Table 6 reveals that there was decrease in current efficiency with respect to time and it is due to the hydrogen evolution side reaction.

Table 6. Effect of contact time on current and recovery efficiency

\begin{tabular}{cccc}
\hline S.No & $\begin{array}{c}\text { Contact time } \\
\text { Hours }\end{array}$ & $\begin{array}{c}\text { Current } \\
\text { efficiency, \% }\end{array}$ & $\begin{array}{c}\text { Recovery } \\
\text { efficiency, \% }\end{array}$ \\
\hline 1 & 3 & 80.18 & 24.44 \\
2 & 6 & 73.35 & 43.175 \\
3 & 9 & 70.49 & 61.37 \\
4 & 12 & 68.19 & 79.54 \\
5 & 13 & 62.97 & 81.81 \\
6 & 14 & 58.47 & 81.81 \\
\hline
\end{tabular}

The discharge of $\mathrm{H}^{+}$ion results in a decrease of their concentration in the vicinity of the cathode. This leads to an increase in $\mathrm{OH}^{-}$concentration near the cathode as a result the metal hydroxide $\mathrm{Ni}(\mathrm{OH})_{2}$ forms and this basic salt may be precipitated thereby reducing the metal ion concentration in the cathode surrounding which leads to decrease in current efficiency. It is also noticed that there is an increase in recovery efficiency with time but after $13^{\text {th }} \mathrm{h}$ contact time there is no improvement in recovery efficiency.

$X R F$ and SEM study of nickel deposited cathode

The X-ray fluorescence (XRF) spectrum of nickel coating on mild steel is capable of measuring the thickness of any coating and qualitative analysis of alloy composition. Energy level for nickel spectrum peak is $7.48 \mathrm{KeV}$ and from the Figure 3 it is observed that the spectrum peak is found around 7, which confirms that the deposited metal is nickel. 


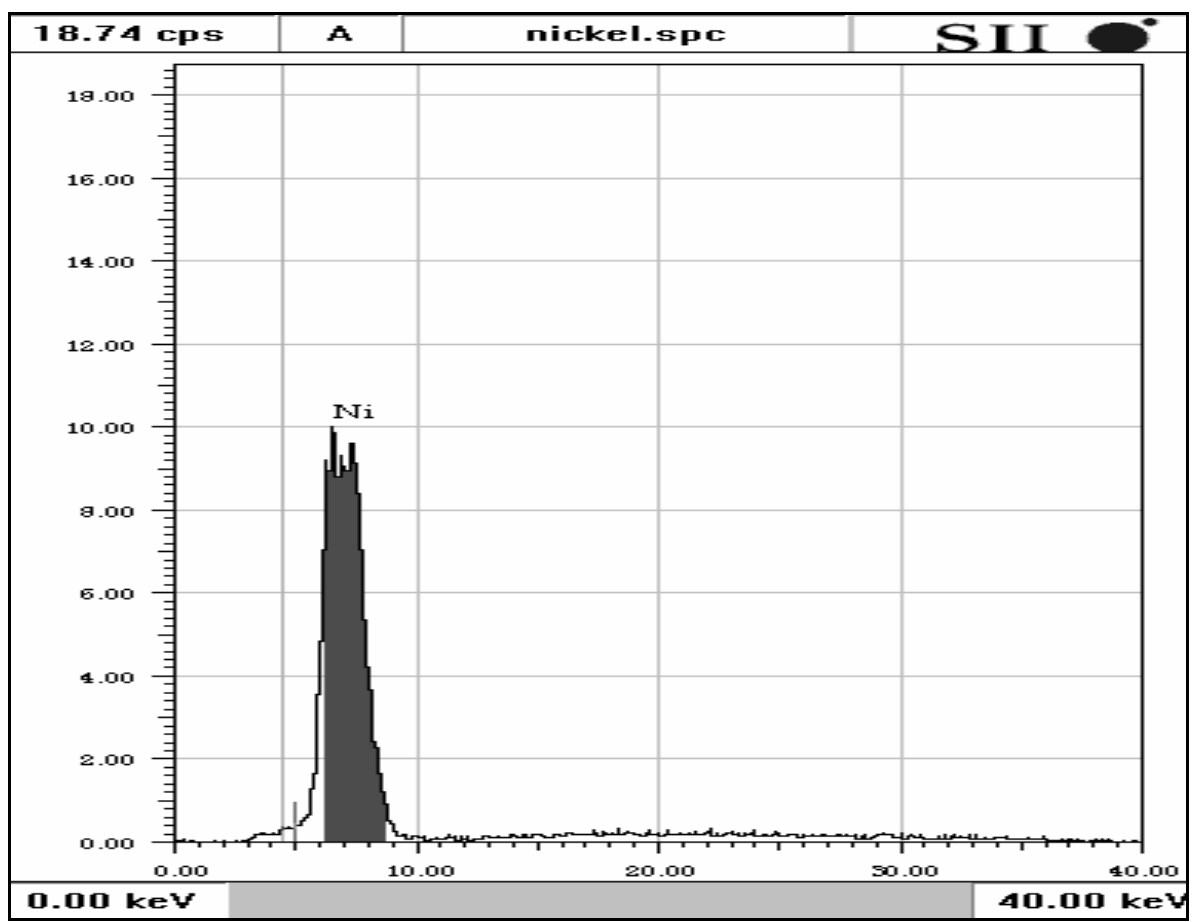

Figure 3. XRF spectrum of the nickel coating on mild steel

Scanning electron microscope photography of nickel coating, mild steel and modified cathode was carried out. From the image of Figure 4, it is very clear that the nickel coating was uniform and cracked. The cracked surface is due to the internal stress present in the coating. Stress may arise from many causes like mismatch of lattice parameters, or incorporation of foreign material such as oxides or hydrated oxides, water, sulfur and carbon, hydrogen, or metallic impurities. These obstruct the formation of normal lattice structures, or they form brittle intergranular deposits.

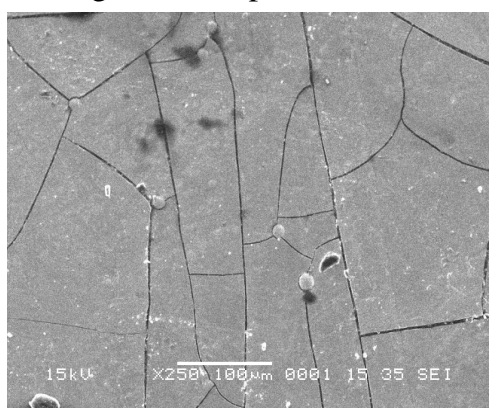

Figure 4. SEM image of nickel coating on mild steel

Here, in the nickel coating the stress may arise due to the incorporation of hydrogen or incorporation of metallic impurities and the main source for hydrogen was due to the hydrogen evolution and the mains source of metallic impurities was the additives which was added to the solution for bath stabilization and this metallic impurities may be co deposited along with nickel. 


\section{Conclusion}

From this study, the following conclusion are made

- To achieve high hydrogen over potential, electrode was modified with gold coating, which resulted in marginal increase in current efficiency for nickel recovery.

- Current efficiency was maximum $(80.18 \%)$ at $5 \mathrm{~A} / \mathrm{dm}^{2}$ current density.

- At the end of $13 \mathrm{~h}$ of electrolytic experiment, removal of nickel was $81.81 \%$ with the current efficiency of $62.97 \%$ and the nickel content was reduced to $0.94 \mathrm{~g} / \mathrm{L}$ from the initial concentration of $5.16 / \mathrm{L}$.

- Scanning electron microscopy image of nickel coating shows major cracks in the surface and these cracks was due to the internal stress of the coating, which makes the coating useful for secondary application only.

\section{Acknowledgment}

Authors are also thankful to the Authorities of Switching Technologies Gunther Ltd, Chennai for providing us the sample of spent electroless nickel solution.

\section{References}

1. Ying wei and Bonk R, United States Patent, 1988, Patent No. 4789484.

2. Rajalakshmi R, Subhashini. S and Lalitha P, E-J Chem., 2009, 6(2), 361-370.

3 Madhavakrishnan S, Manickavasagam K, Rasappan K, Syed Shabudeen P S, Venkatesh R and Pattabhi S, E-J Chem., 2008, 5(4), 761-769.

4. Kadirvelu K, Thamaraiselvi K and Namasivayam C, Separation and Purification Technology, 2001, 24, 497-505.

5. Rengaraj S, Yeon. K H, Kang S Y, Lee J U, Kim K W and Moon S H, J Hazard Mater., 2002, 89,185-196.

6. Parthasaradhy N V, 1988, Practical Electroplating Handbook. Prentice Hall, Englewood Cliffs, New Jersey.

7. Blatt W and Schneider L, Galvanotechnik, 1996, 87, 1118 - 1124.

8. Orhan G, Arslan C, Bombach H and Stelter M, Hydrometallurgy, 2002, 65, 1-8.

9. Sirajuddin, Kakakhel L, Lutfullah G and Marwat R U, Acta Chim Slov, 2004, 51, 793-798

10. Puippe J C, Galvanotechnik, 1995, 86, 2124- 2129.

11. Ripperger S, Galvanotechnik, 1984, 75, 566-569.

12. Vogel A I, Textbook of quantitative inorganic analysis including elementary instrumental analysis, ELBS $4^{\text {th }}$ Edition, 1978, 322. 


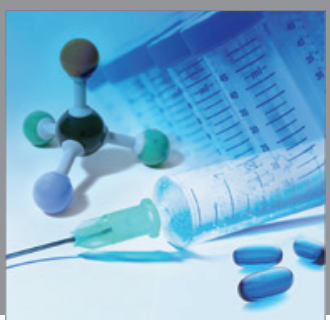

International Journal of

Medicinal Chemistry

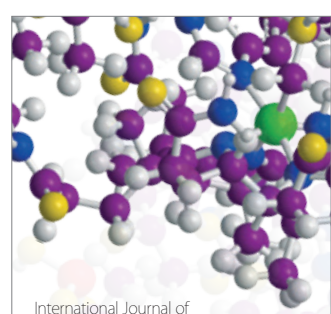

Carbohydrate Chemistry

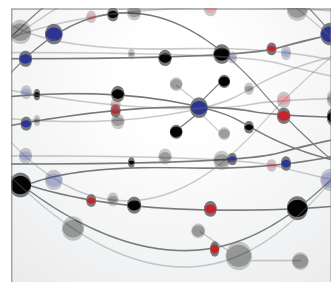

The Scientific World Journal
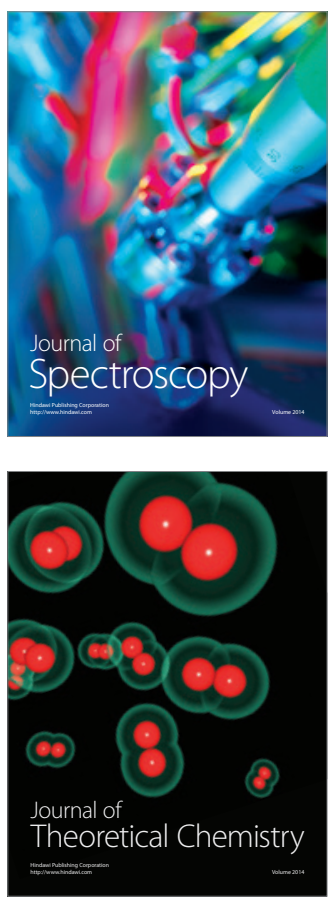
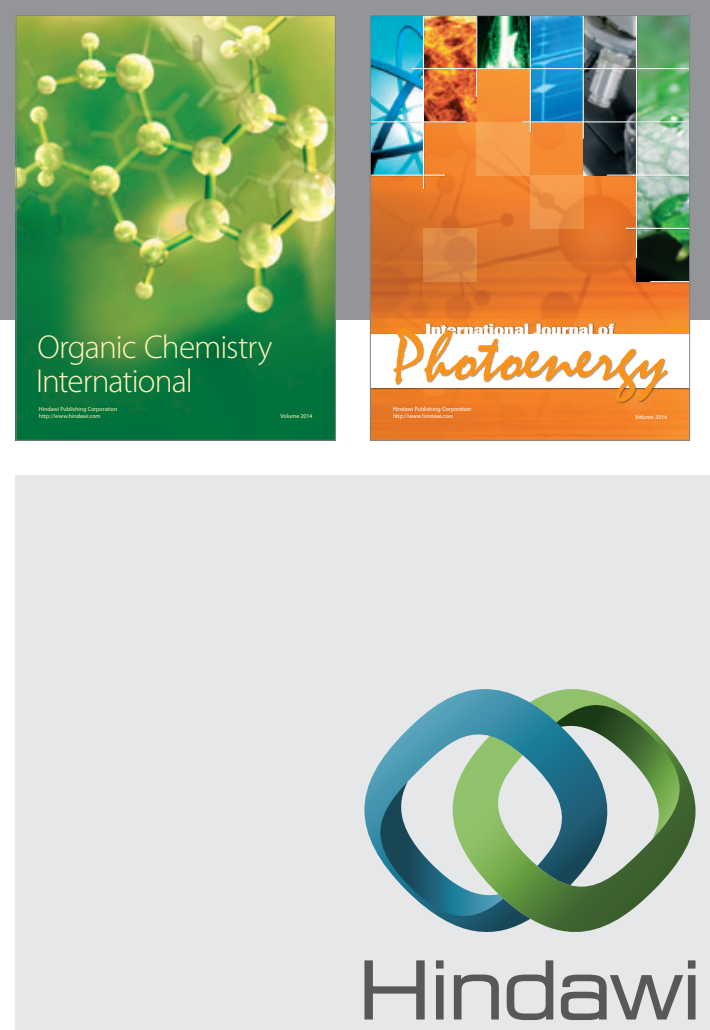

Submit your manuscripts at

http://www.hindawi.com
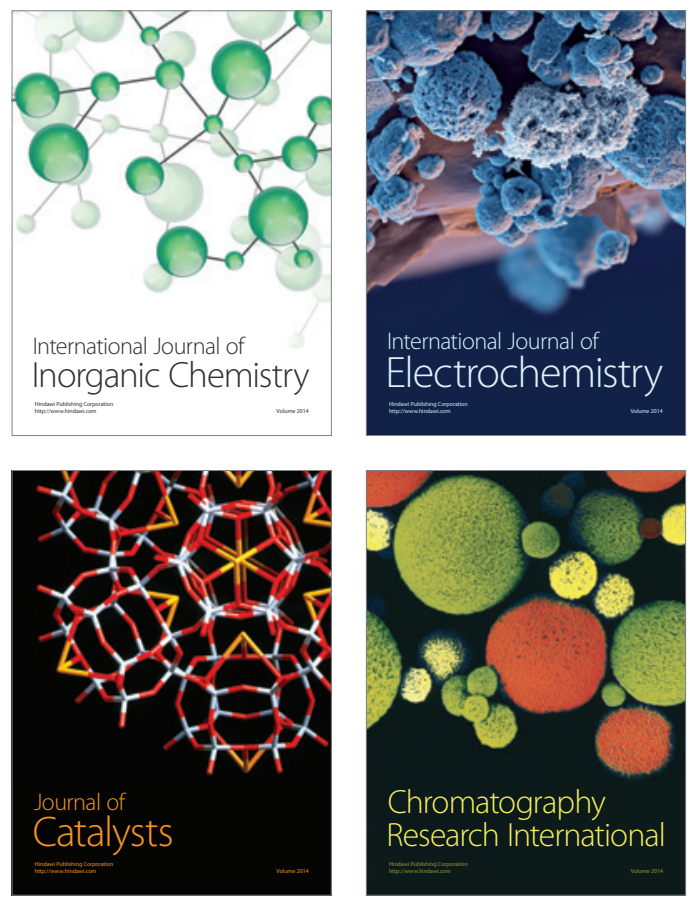
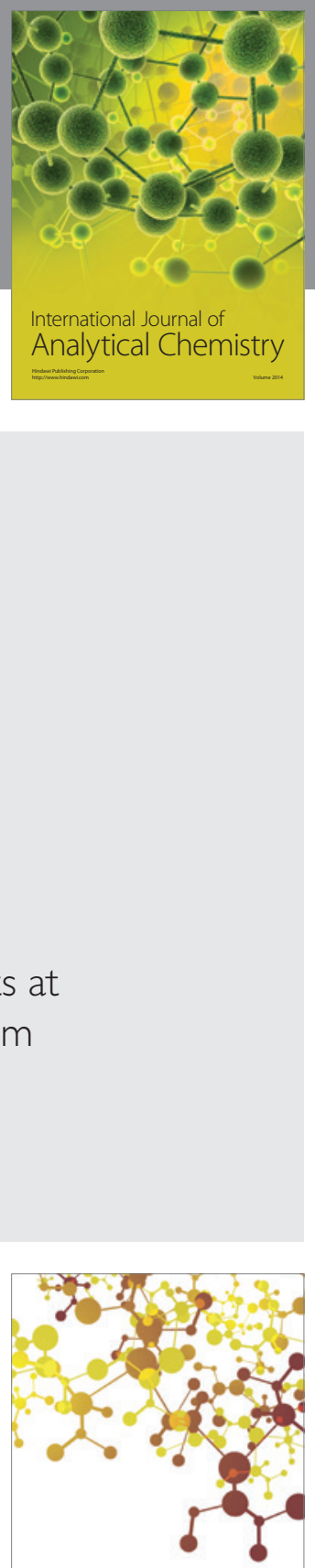

Journal of

Applied Chemistry
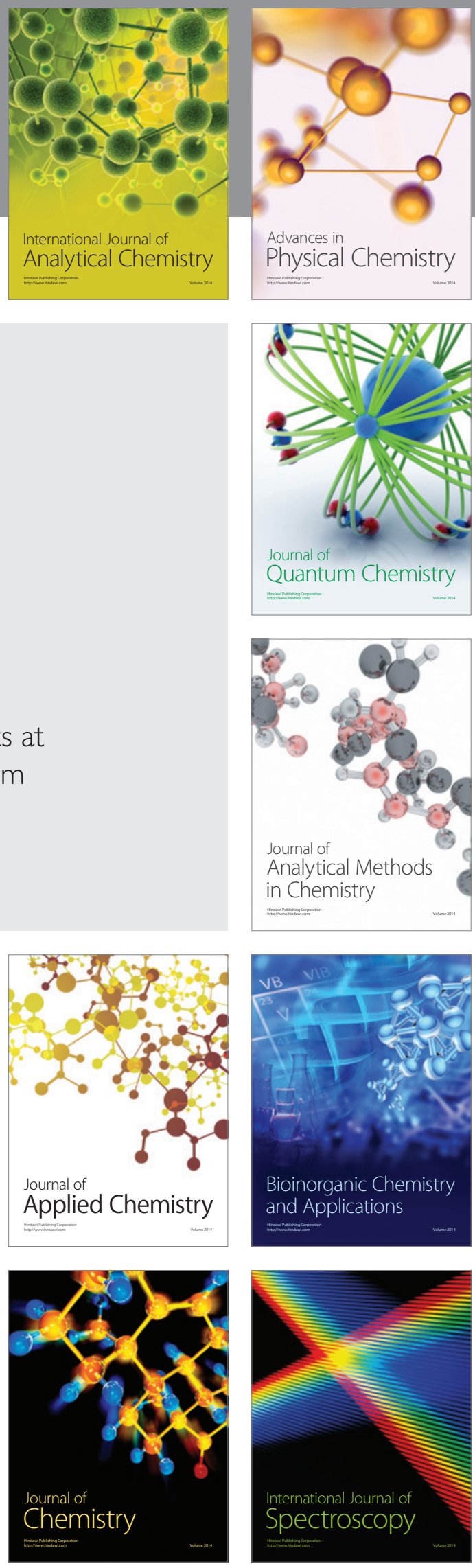